\title{
Determination of aristolochic acid in Chinese herbal medicine by capillary electrophoresis with laser-induced fluorescence detection
}

\author{
Shih-Chung Hsieh ${ }^{\mathrm{a}, \mathrm{b}}$, Ming-Feng Huang ${ }^{\mathrm{c}}$, Bing-Shi Lin ${ }^{\mathrm{a}, \mathrm{d}}$, Huan-Tsung Chang ${ }^{\mathrm{c}, *}$ \\ ${ }^{a}$ Division of Nephrology, Shin Kong Wu Ho-Su Memorial Hospital, Taipei, Taiwan \\ ${ }^{\mathrm{b}}$ Department of Medicine, Taipei Medical University, Taipei, Taiwan \\ ${ }^{\mathrm{c}}$ Department of Chemistry, National Taiwan University, 1 Roosevelt Road Section 4, Taipei 10674, Taiwan \\ ${ }^{\mathrm{d}}$ Department of Medicine, National Yang-Ming University, Taipei, Taiwan
}

Available online 11 August 2005

\begin{abstract}
We have demonstrated the analysis of aristolochic acids (AAs) that are naturally occurring nephrotoxin and carcinogen by capillary electrophoresis in conjunction with laser-induced fluorescence detection (CE-LIF). Owing to lack of intrinsic fluorescence characteristics of oxidized AAs (OAAs), reduction of the analytes by iron powder in $10.0 \mathrm{mM} \mathrm{HCl}$ is required prior to CE analysis. The reduced AAs (RAAs) exhibit fluorescence at $477 \mathrm{~nm}$ when excited at $405 \mathrm{~nm}$ using a solid-state blue laser. By using $50.0 \mathrm{mM}$ sodium tetraborate (pH 9.0) containing $10.0 \mathrm{mM}$ SDS, the determination of AA-I and AA-II by CE-LIF has been achieved within $12 \mathrm{~min}$. The CE-LIF provides the LODs of 8.2 and $5.4 \mathrm{nM}$ for AA-I and AA-II, respectively. The simple CE-LIF method has been validated by the analysis of 61 Chinese herbal samples. Prior to $\mathrm{CE}$ analysis, OAAs were extracted by using $5.0 \mathrm{~mL} \mathrm{MeOH}$, and then the extracts were subjected to centrifugation at $3000 \mathrm{rpm}$ for $5 \mathrm{~min}$. After reduction, extraction, and centrifugation, the supernatants were collected and subjected to CE analysis. Of the 61 samples, 14 samples contain AA-I and AA-II, as well as 10 samples contain either AAI or AAII. The relative standard deviation (RSD) values of the migration times for AA-I and AA-II are less than $2.5 \%$ and $2.1 \%$ for three consecutive measurements of each sample. The RSD values for the peak heights corresponding to AA-I and AA-II in most samples are about $8.0 \%$ and $10.0 \%$, respectively. The result shows that the present CE-LIF approach is sensitive, simple, efficient, and accurate for the determination of AAs in real samples.
\end{abstract}

(C) 2005 Elsevier B.V. All rights reserved.

Keywords: Aristolochic acids; Capillary electrophoresis; Chinese herbal medicine; Laser-induced fluorescence

\section{Introduction}

Aristolochic acids (AAs), a family of structurally related nitrophenanthrene carboxylic acids, are found naturally in medicinal plants such as Radix aristolochiae or herbs such as Aristolochia spp. [1]. The herbs sold on the Asian market are used to relieve pain by subdueing hyperactivity of the liver, to induce diuresis, as well as to control weight [2-4]. In the early 1990s, ingestion of AAs was incriminated in the outbreak of the so-called Chinese herbs nephropathy $(\mathrm{CHN})$, severe tubulointerstitial nephritis $[5,6]$. In addition to a rapidly progressive interstitial renal failure due to particularly severe fibrosis, the clinical course of $\mathrm{CHN}$ is complicated by tumor

\footnotetext{
* Corresponding author. Tel.: +886 223621963; fax: +886 223621963

E-mail address: changht@ntu.edu.tw (H.-T. Chang).
}

transformations in the urothelium [7]. Many countries including UK, Canada, Australia, and Germany have announced banning to restrict the importation, sale, and use of AAcontaining medicines like Aristolochia fangchi and Mutong [8]. In 2001, the Food and Drug Administration (FDA) in USA issued warnings and an important alert that herbal products are unsafe if they contain or are suspected to contain AA [9]. In the November of 2003, five Chinese herbal drugs containing AAs were officially banned in Taiwan. Despite the action of the FDA and the effort of many countries, 19 products containing AAs and 95 products suspected to contain AAs were for sale on the Web in 2003 [10]. Because AAs have threatened the public health, there is still a need to develop simple, sensitive and effective methods to detect the presence of AAs in Chinese herbs remedies and dietary supplements. 
There are many AAs, including two predominant ones that are 8-methoxy-6-nitrophenanthro-(3,4-d)-1,3-dioxolo5-carboxylic acid (AA-I) and 6-nitro-phenanthro-(3,4-d)1,3-dioxolo-5-carboxylic acid (AA-II). The analysis of AA-I and AA-II is difficult mainly because of their extremely similar structures and identical medicinal activities. Thin layer chromatography (TLC) [11-13], UV-vis absorption [14] and high performance liquid chromatography (HPLC) with UV-vis absorption detection (HPLC/UV) [15-18] have been applied to the analyses of AA-I and/or AA-II in samples. In order to further confirm the structural identification of compositions of Chinese herbs, HPLC with quadrupole ion-trap mass spectrometry (MS) and with electrospray ion-trap MS detection have been employed [19-21]. Quantitative determinations of AA-I in the incriminated preparations were also demonstrated using both UV-vis absorption and MS detection [22].

Capillary electrophoresis (CE) provides the advantages over HPLC, including high speed, efficiency, and requiring minute amounts of samples and reagents, and has proved to be a powerful tool for the analysis of polar and thermally labile compounds [23]. Analyses of natural medicines and natural products by $\mathrm{CE}$ have been well documented, especially in Chinese Society [24-26]. CE with UV-vis absorption detection has been developed for the analysis of AA-I and AA-II in Chinese prepared medicines (CPMs) after pressurized liquid extraction $[27,28]$. The limits of detection (LODs) at a signalto-noise ratio $(\mathrm{S} / \mathrm{N})=3$ for AA-I and AA-II were found to be 1.2 and $0.9 \mathrm{mg} / \mathrm{L}$ (3.5 and $2.9 \mathrm{mM}$ ), respectively. Because of poor sensitivity and less selectivity, the method required great amounts of samples and reagents, as well as tedious sample preparations. In addition, most solutes in CPMs absorb UV light, which cause analysis errors when co-migration of the analytes takes place.

The aim of this work was to develop a simple, rapid, and sensitive method for the determinations of AA-I and AAII in medicinal samples and dietary supplements by CE. In order to provide great sensitivity, laser-induced fluorescence (LIF) detection was employed in the CE system. Because AAs have weak/no fluorescence, their nitro groups have to be reduced to amino groups in order to achieve high sensitivity of CE-LIF. The reduction of the nitro group was performed in acidic solutions containing iron powder [29,30]. We carefully evaluated parameters such as organic additives, surfactants, $\mathrm{pH}$, and ionic strength that affect the separation selectivity and speed, as well as detection sensitivity of the method. The proposed method was also validated by the analyses of 61 medicinal samples and dietary supplements.

\section{Materials and methods}

\subsection{Standard chemicals}

AAs, sodium tetraborate, and iron powder (325-mesh) were purchased from Acros organics (New Jersey, USA). The
AA standard contains $90 \%$ AA-I and 10\% AA-II. Methanol of analytical reagent grade was obtained from Mallinckrodt (Phillipsburg, NJ, USA). Sodium dodecyl sulfate (SDS) was obtained from Sigma (St. Louis, MO, USA). Sodium hydroxide and hydrochloric acid were obtained from Riedelde Haën (Seelze, Germany). Ethylenediaminetetraacetic acid (EDTA) was purchased from Kanto Chemical (Tokyo, Japan). Sodium tetraborate solutions $(10.0-70.0 \mathrm{mM})$ were adjusted with $1.0 \mathrm{M} \mathrm{HCl}$ or $0.5 \mathrm{M} \mathrm{NaOH}$ to the desired $\mathrm{pH}$ values (4.0-9.0).

\subsection{Medicinal samples}

The medicinal samples and dietary supplements used in this study were either obtained from patients or purchased from local drug stores. Patients who have taken these herbs medicines or dietary supplements for some times are suspected to be the case of CHN in the Shin Kong Wu Ho-Su Memorial Hospital (Taipei, Taiwan). Most of the herb medicines or dietary supplements are powder, and some are either pills or capsules. The samples in a pill formulation were ground into fine powder before conducting sample preparation. The sugar shells of capsules were removed and the fine powders were used for further sample preparation.

\subsection{Sample preparation}

Approximately $0.20 \mathrm{~g}$ of the medicinal powders and dietary supplements were dissolved in aliquots of $5.0 \mathrm{~mL}$ of $\mathrm{MeOH}$. In order to ensure completed dissolution of the powders in methanol, the solutions were subjected to ultrasonication at room temperature for $30 \mathrm{~min}$. The solutions were then subjected to centrifugation at $3000 \mathrm{rpm}$ for $5 \mathrm{~min}$ and the supernatants were carefully collected by pipetting.

\subsection{Reduction of AA-I and AA-II}

For simplicity, hereafter the oxidized AA-I and AA-II are denoted by OAA-I and OAA-II, while their reduced forms are denoted by RAA-I and RAA-II, respectively. The stock OAA solution was prepared by dissolving $2.0 \mathrm{mg}$ standard mixture of OAA-I (90\%) and OAA-II (10\%) in methanol into a $10.0 \mathrm{~mL}$ volumetric flask. The reductions of OAAI and OAA-II were conducted by adding $173.0 \mu \mathrm{L}$ of the stock OAA solution to $10.0 \mathrm{~mL}$ of $10.0 \mathrm{mM} \mathrm{HCl}$ solution containing $10.0 \mathrm{mg}$ iron powder. Under this condition, most iron powder was not dissolved. The concentrations of OAA-I and OAA-II in thus-prepared solution are $9.0 \times 10^{-6} \mathrm{M}$ and $10^{-6} \mathrm{M}$, respectively. The solutions were stirred by using a magnetic stirrer at room temperature for $40 \mathrm{~min}$ unless otherwise noted, during which time the solution changed color from pale yellow to colorless. When conducting reduction of OAAs from the real samples, instead of $173.0 \mu \mathrm{L}$ of the stock AA solution, aliquots of $1.0 \mathrm{~mL}$ of the super- 


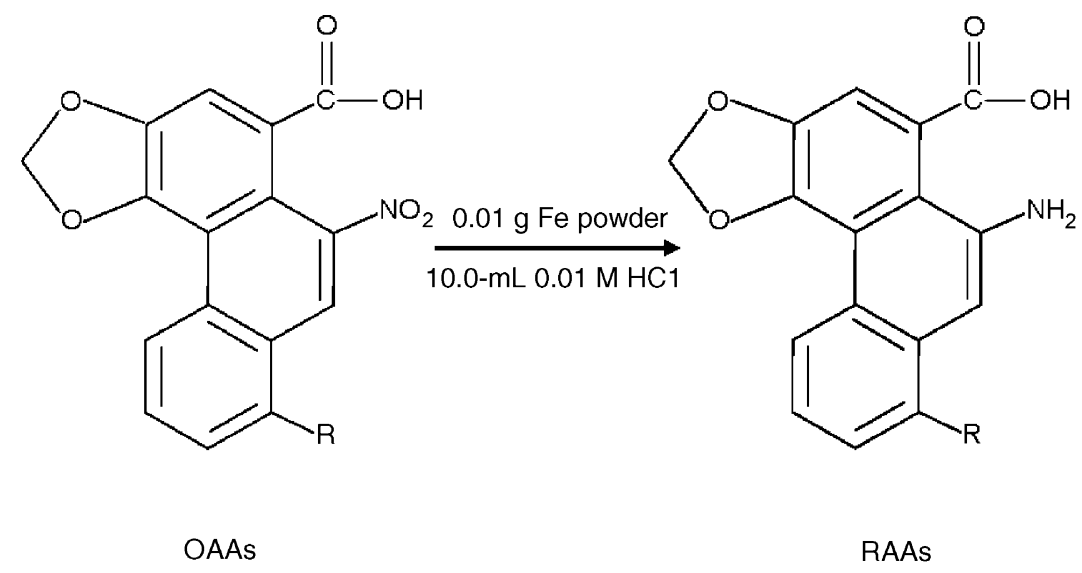

$(\mathrm{R}=\mathrm{OCH} 3$ for $\mathrm{AA} \mathrm{I}$, and $\mathrm{R}=\mathrm{H}$ for $\mathrm{AA} I \mathrm{I})$

Fig. 1. Reduction of OAAs to RAAs by $0.01 \mathrm{~g}$ iron powder in $10.0 \mathrm{mM} \mathrm{HCl}$. $\mathrm{R}$ separately represents $\mathrm{OCH}_{3}$ and $\mathrm{H}$ in OAA-I and OAA-II.

natants were separately added to vials containing $9.0 \mathrm{~mL}$ of $10.0 \mathrm{mM} \mathrm{HCl}$ solution and $10.0 \mathrm{mg}$ iron powder. Fig. 1 exhibits the reaction of OAAs to RAAs. For fluorescence, IR, MS, ${ }^{1} \mathrm{H}$ NMR, and UV-vis absorption measurements, $5.0 \mathrm{~mL}$ of the stock AA solution $(0.2 \mathrm{mg} / \mathrm{mL})$ was added to $95.0 \mathrm{~mL}$ of $10.0 \mathrm{mM} \mathrm{HCl}$ solution containing $0.1 \mathrm{~g}$ iron powder. After the reduction was completed, RAAs were extracted from aqueous solution to $\mathrm{CH}_{2} \mathrm{Cl}_{2}$. To obtain RAA powder, the $\mathrm{CH}_{2} \mathrm{Cl}_{2}$ layer was collected and dried by using a rotary evaporator at $30^{\circ} \mathrm{C}$. The powder was then re-dissolved in buffers or in organic solvent $\left(\mathrm{CD}_{3} \mathrm{OD}\right)$, or mixed with $\mathrm{KBr}$ (details see Section 2.5).

\subsection{Characterization}

A double-beam UV-vis spectrophotometer (Cintra 10e, GBC Scientific Equipment Pty Ltd., Dandenong, Victoria, Australia) was used to measure the absorption values of $10^{-5} \mathrm{M}$ OAAs and RAAs solutions. Fluorescence spectra were recorded using a fluorometer (Aminco-Bowman Series 2, ThermoSpectronic, Pitsford, NY, USA). Prior to UV-vis absorption and fluorescence measurements, the OAAs and RAAs powders were separately dissolved in $3.0 \mathrm{~mL}$ methanol, and then diluted to $1 / 50$ with $50.0 \mathrm{mM}$ sodium tetraborate ( $\mathrm{pH}$ 2.0-9.0). An IR spectrophotometer (MAGAN-IR 550, Nicolet, New York, NY, USA) was used to collect the IR spectra of the OAAs and RAAs. The powders were separately mixed with $\mathrm{KBr}$ powder by a ratio of 1:5 $(\mathrm{w} / \mathrm{w})$ and then the mixtures were platted to a thin pill prior to IR measurements. A FAB MS (JOEL SX-102A, JOEL, Peabody, MA, USA) was used to measure the mass spectra of OAAs and RAAs. The samples were prepared by dissolving OAAs and RAAs powder in nitrobenzene alcohol matrix. For collecting the ${ }^{1} \mathrm{H}$ NMR spectra using a Varian $400 \mathrm{MHz}$ NMR (Palo Alto, CA, US), $1.0 \mathrm{mg}$ OAA and RAA powder were separately dissolved in $1-\mathrm{mL} \mathrm{CD}_{3} \mathrm{OD}$.

\subsection{CE-LIF apparatus}

The basic design of the separation system has been previously described [31]. Briefly, a high-voltage power supply (Gamma High Voltage Research Inc., Ormond Beach, FL, USA) was used to drive electrophoresis. The entire detection system was enclosed in a black box with a high-voltage interlock. The high-voltage end of the separation system was housed in a plexiglass box for safety. A 4.0-mW solid state laser with $405 \mathrm{~nm}$ output from B\&WTEK Inc. (Newark, DE) was used for excitation. The emission light was collected with a $10 \times$ objective (numeric aperture $=0.25$ ). One RG 450 cutoff filter was used to block scattered light before the emitted light reached the phototube (R928, Hamamatsu Photonics K. K., Shizuoka-Ken, Japan). The fluorescence signal was transferred directly through a $10-\mathrm{k} \Omega$ resistor to a $24-$ bit A/D interface (CSW chromatographic station; DataApex Ltd., Czech Republic) at $10 \mathrm{~Hz}$ and stored in a PC. Capillaries with $75 \mu \mathrm{m}$ I.D. and $365 \mu \mathrm{m}$ O.D. were from Polymicro Technologies (Phoenix, AZ, USA).

\subsection{CE conditions and quantitative analysis}

The 40-cm capillary was rinsed with $0.5 \mathrm{~N} \mathrm{NaOH}$ overnight prior to use for electrophoresis. The RAA sample was injected into a capillary filled with $10-70.0 \mathrm{mM}$ sodium tetraborate containing 0-30.0 mM SDS ( $\mathrm{pH} 9.0)$ at $20-\mathrm{cm}$ height for $10 \mathrm{~s}$. The separation was conducted at $10 \mathrm{kV}$. Between consecutive runs, the capillary was flushed with the running buffer for $1 \mathrm{~min}$ to guarantee good reproducibility. In order to determine the concentrations of the analytes, $100.0 \mu \mathrm{L}$ of RAAS standard solutions $\left(10^{-5}\right.$ to $\left.5 \times 10^{-7} \mathrm{M}\right)$ were spiked into $900.0 \mu \mathrm{L}$ of sample solutions. Linear plots of the peak heights against the concentrations of the standards were depicted and the plots were used to determine the concentrations of the analytes in the samples. 


\section{Results}

\subsection{Reduction of OAAs and characterization}

Oxidative enzymes such as hepatic microsomal CYP1A1/2, NADPH:CYP reductase, DT-diaphorase and cyclooxydase-1 cause reduction of the nitro group in AA-I and AA-II to form reactive cyclic nitrenium ions [32,33]. In the presence of iron powder at $\mathrm{pH} 2.0$, we anticipated that the nitro groups in OAA-I and OAA-II were reduced to amino groups and thus RAA-I and RAA-II formed, respectively, as shown in Fig. 1. In order to identify the products, IR, NMR, and MS measurements were performed. Table 1 lists some of the IR, NMR, and MS data for OAAs and RAAs. The disappearance of $\mathrm{NO}_{2}$ signals in IR $\left(1347,1525\right.$, and $\left.1594 \mathrm{~cm}^{-1}\right)$ and $\mathrm{MS}(\mathrm{m} / \mathrm{z}=341$ and $312)$ as well as the appearance of $\mathrm{NH}_{2}$ signals in the spectra of IR (1635 and $\left.3220 \mathrm{~cm}^{-1}\right)$, NMR ( $\delta=0.87$ and 5.30), and MS $(m / z=311$ and 282) strongly support the formation of RAAs. Differential UV-vis absorption and fluorescence characteristics between OAAs and RAAs further support our reasoning.

Fig. 2A clearly exhibits that OAAs and RAAs possess differential UV-vis absorption spectra. The absorption bands of OAAs at 219, 251 and $316 \mathrm{~nm}$ correspond to the carboxyl group, conjugated olefin group (aromatic compounds), and nitro group, respectively. A broad absorption band between
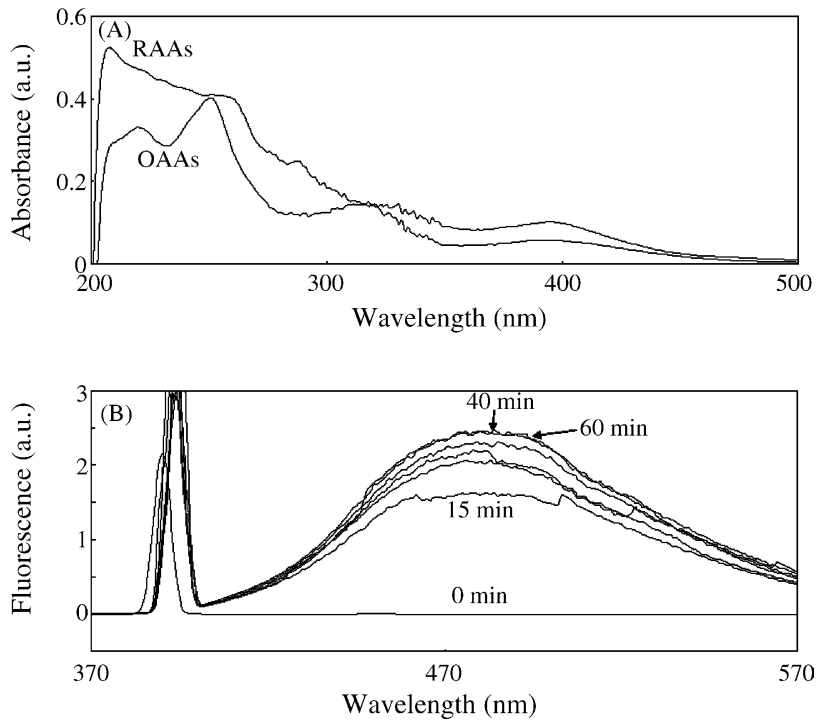

Fig. 2. (A) UV-vis spectra of OAAs and RAAs in $50.0 \mathrm{mM}$ sodium tetraborate solution at $\mathrm{pH}$ 9.0. (B) Time evolution of fluorescence spectra of RAAs. The excitation wavelength is $390 \mathrm{~nm}$ and the emission wavelength is $477 \mathrm{~nm}$.

225 and $288 \mathrm{~nm}$ for the RAAs further suggests the formation of aniline compounds [34]. Although the absorbance values at $316 \mathrm{~nm}$ for the OAAs and RAAs are close, there is no apparent band at $316 \mathrm{~nm}$ in RAAs as that in OAAs. Fig. 2B

Table 1

Comparisons of OAAs and RAAs with respect to IR, ${ }^{1} \mathrm{H}$ NMR, Mass, UV-vis absorption, and fluorescence data

\begin{tabular}{|c|c|c|}
\hline Spectrochemical methods & OAAs & RAAs \\
\hline IR (wavelength, $\mathrm{cm}^{-1}$ ) & $\begin{array}{l}1270\left(\mathrm{R}-\mathrm{O}-\mathrm{CH}_{3}\right) \\
1347\left(\mathrm{R}-\mathrm{NO}_{2}\right) \\
1525\left(\mathrm{R}-\mathrm{NO}_{2}\right) \\
1642 \text { (aromatic ring) } \\
1659 \text { (aromatic ring) } \\
1594\left(\mathrm{R}-\mathrm{NO}_{2}\right) \\
1697(\mathrm{C}=\mathrm{O} \text { stretching) }\end{array}$ & $\begin{array}{l}1044\left(\mathrm{R}-\mathrm{O}-\mathrm{CH}_{3}\right) \\
1270\left(\mathrm{R}-\mathrm{O}-\mathrm{CH}_{3}\right) \\
1607 \text { (aromatic ring) } \\
1642 \text { (aromatic ring) } \\
1659 \text { (aromatic ring) } \\
1635(\mathrm{~N}-\mathrm{H} \text { bending) } \\
3220(\mathrm{~N}-\mathrm{H} \text { stretching) }\end{array}$ \\
\hline${ }^{1} \mathrm{H}$ NMR (ppm) & $\begin{array}{l}1.23\left(\text { saturated }-\mathrm{CH}_{3}\right) \\
1.60(\text { saturated }-\mathrm{CH}) \\
2.15(\mathrm{Ar}-\mathrm{CH}) \\
4.04(-\mathrm{OMe}) \\
6.37(\mathrm{Ar}-\mathrm{H}) \\
7.24(\mathrm{Ar}-\mathrm{H})\end{array}$ & $\begin{array}{l}0.87\left(\mathrm{R}_{2}-\mathrm{NH}\right) \\
1.23\left(\text { saturated }-\mathrm{CH}_{3}\right) \\
1.60(\text { saturated }-\mathrm{CH}) \\
1.86(\text { saturated }-\mathrm{CH}) \\
1.99(\text { saturated }-\mathrm{CH}) \\
4.01(-\mathrm{OMe}) \\
4.04(-\mathrm{OMe}) \\
5.30\left(\mathrm{Ar}-\mathrm{NH}_{2}\right) \\
6.37(\mathrm{Ar}-\mathrm{H}) \\
7.24(\mathrm{Ar}-\mathrm{H})\end{array}$ \\
\hline $\operatorname{Mass}(m / z)^{\mathrm{a}}$ & $\begin{array}{l}312\left[M 1+\mathrm{H}-\mathrm{OCH}_{2}\right]^{+},[M 2+\mathrm{H}]^{+} \\
341[M 1]^{+\mathrm{b}}\end{array}$ & $\begin{array}{l}282\left[M 1+\mathrm{H}-\mathrm{OCH}_{2}\right]^{+},[M 2+\mathrm{H}]^{+} \\
311[M 1]^{+\mathrm{b}}\end{array}$ \\
\hline UV-vis absorption (nm) & $\begin{array}{l}219(-\mathrm{COOH}) \\
251(\text { Triolefin, aromatic ring) } \\
316\left(-\mathrm{NO}_{2}\right) \\
395\end{array}$ & $\begin{array}{l}225\left(\mathrm{Ar}-\mathrm{NH}_{2}\right) \\
259 \\
288\left(\mathrm{Ar}-\mathrm{NH}_{2}\right) \\
395\end{array}$ \\
\hline Fluorescence (nm) & None & $\lambda_{\mathrm{ex}}=390 \mathrm{~nm} ; \lambda_{\mathrm{em}}=477 \mathrm{~nm}$ \\
\hline
\end{tabular}

a $M 1$ and $M 2$ represent the formular weights of AA-I and AA-II, respectively.

b The peaks for OAAs and RAAs are not shown as the base peaks. 
exhibits that OAAs ( $\mathrm{pH} 2.0$ ) do not fluoresce at $477 \mathrm{~nm}$ when excited at $390 \mathrm{~nm}$, but the solution fluoresced in the presence of iron powder. The fluorescence reached a plateau at the reaction time of $40 \mathrm{~min}$, suggesting that the formation of RAAs from the reduction of OAAs was completed within $40 \mathrm{~min}$. The reason that OAAs do not fluoresce is mainly because of quenching caused by $\mathrm{NO}_{2}$ group (withdrawing group). Increases in fluorescence with increasing $\mathrm{pH}$ in the range of 2.0-9.0 suggest that an intra hydrogen bond formed between the amino group and carboxylate in RAAs. As a result of formation of a rig structure, the RAAs molecules rotated to a less extent and thus fluoresced more strongly. The fluorescence intensity at $\mathrm{pH} 8.0$ was about 1.6 times higher than that at $\mathrm{pH}$ 2.0. Because there were $\mathrm{Fe}^{3+}$ ions in the solution, it is possible that the increase in fluorescence was due to the formation of RAAs-Fe(III) complexes. To test the possibility, we added EDTA that forms a strong complex with $\mathrm{Fe}^{3+}$ at the concentration ranges $10^{-2}$ to $10^{-6} \mathrm{M}$ to the RAAs solution ( $\mathrm{pH}$ 9.0). The fact of slight changes in the fluorescence intensity in the presence of EDTA rules out the possibility of forming RAAs-Fe(III) complexes.

\subsection{Optimization of CE separation and LIF detection}

In addition to low quantum yields at low $\mathrm{pH}$ values $(<4.0)$, RAA-I and RAA-II were not separated in the baseline, mainly because they have similar structures and their amino groups are both fully protonated. Thus we focused on evaluating parameters that affect the separation speed, resolution, sensitivity, and reproducibility at the $\mathrm{pH}$ values ranging from 4.0 to 9.0 , including compositions, $\mathrm{pH}$, and ionic strength of the background electrolytes, additives (SDS), and applied voltage.

To minimize the quenching caused by Joule heats and the loss of resolution due to analyte adsorption, selection of a suitable background electrolyte in CE-LIF is extremely important. On the basis of our previous study [35], we have learned that sodium tetraborate buffer provides higher separation efficiency and sensitivity for amines than do phosphate or carbonate buffer solution. We thus used $50 \mathrm{mM}$ tetraborate solutions to test the $\mathrm{pH}$ dependence of the separation resolution and reproducibility of RAAs in CE-LIF. In the $\mathrm{pH}$ range of 4.0-9.0, we found that the separation is proper at
$\mathrm{pH} 9.0$ mainly because the EOF is constant as well as minimum analyte adsorption. At $\mathrm{pH}$ value above 7.0, the analyes migrated with high electrophoretic mobilities against high EOF. The instability of RAAs and high Joule heats generated that caused fluorescence quenching and irreproducibility are problematic at $\mathrm{pH}>9.0$.

Next we tested the ionic strength dependence of the sensitivity and resolution of RAA-I and RAA-II at pH 9.0. The electrophoretic mobilities of RAA-I and RAA-II decreased with increasing ionic strength in the concentration range of 10.0-70.0 mM tetraborate solutions ( $\mathrm{pH} 9.0)$. The resolution values between RAA-I and RAA-II in 10.0, 30.0, 50.0, and $70.0 \mathrm{mM}$ tetraborate solutions were $1.5,1.7,2.1$, and 0 , respectively. One other drawback of using $70 \mathrm{mM}$ tetraborate solutions is a significant quenching of the fluorescence signals of RAAs, mainly due to Joule heats (collision). Our reasoning is supported by the fact that the currents were 15.0 and $190.0 \mu \mathrm{A}$ in 10.0 and $70.0 \mathrm{mM}$ tetraborate solutions (pH 9.0), respectively. Although quenching and Joule heats increased with increasing tetraborate concentration, the efficiency was greater in $50 \mathrm{mM}$ tetraborate solution as a result of smaller analyte adsorption. Capillaries with small sizes such as 50 and $25 \mu \mathrm{m}$ in diameter can be used to reduce the effect of Joule heating, but more difficulty of alignment, problems of analyte adsorption, and loss of sensitivity must be evaluated.

Although $50 \mathrm{mM}$ tetraborate buffer $(\mathrm{pH} 9.0)$ provides the baseline separation between RAA-I and RAA-II within 8 min, the peak widths of the RAAs were both wider than $0.4 \mathrm{~min}$. In order to decrease the peak width and thus improve efficiency, SDS was added to the background electrolyte. Table 2 lists the effect of SDS on speed, resolution, sensitivity, and reproducibility for the separation of RAA-I and RAA-II, exhibiting that $10.0 \mathrm{mM}$ SDS is proper. We note that a high fluorescence background and quenching caused by Joule heats are problematic at high SDS concentrations $(>20.0 \mathrm{mM})$. Fig. 3 presents the separation of standard RAAI and RAA-II at $10 \mathrm{kV}$ using $50.0 \mathrm{mM}$ tetraborate buffer (pH 9.0) containing $10.0 \mathrm{mM}$ SDS. At the separation condition, SDS molecules (critical micelle concentration $8.3 \mathrm{mM}$ ) formed micelles, leading to longer migration times for the RAAs because they participated in aqueous solution and micelles. The increase in the separation time was partially

Table 2

Effect of SDS on speed, resolution, sensitivity, and reproducibility for RAA-I and RAA-II by CE-LIF ${ }^{\mathrm{a}}$

\begin{tabular}{|c|c|c|c|c|c|}
\hline \multirow[t]{2}{*}{ SDS (mM) } & \multicolumn{2}{|c|}{ Migration time $(\min )(\mathrm{RSD})^{\mathrm{b}}$} & \multirow{2}{*}{$\begin{array}{l}\text { Resolution }\left(R_{\mathrm{S}}\right)^{\mathrm{c}} \\
\text { RAA-II/RAA-I }\end{array}$} & \multicolumn{2}{|c|}{$\operatorname{LOD}\left(10^{-8} \mathrm{M}\right)(\mathrm{RSD})^{\mathrm{b}}$} \\
\hline & RAA-II & RAA-I & & RAA-II & RAA-I \\
\hline 0 & $7.51(0.6 \%)$ & $8.35(0.8 \%)$ & 2.1 & $2.05(3.9 \%)$ & $2.79(4.2 \%)$ \\
\hline 5 & $8.16(0.6 \%)$ & $8.85(0.7 \%)$ & 2.4 & $1.32(4.1 \%)$ & $1.69(4.4 \%)$ \\
\hline 10 & $9.42(0.5 \%)$ & $10.28(0.7 \%)$ & 3.1 & $0.54(4.5 \%)$ & $0.82(5.3 \%)$ \\
\hline 20 & $14.64(1.1 \%)$ & $15.18(1.2 \%)$ & 1.6 & $0.72(4.9 \%)$ & $1.05(5.9 \%)$ \\
\hline 30 & $21.22(3.1 \%)$ & $21.58(3.5 \%)$ & 0.6 & $1.48(5.8 \%)$ & $2.62(7.1 \%)$ \\
\hline
\end{tabular}




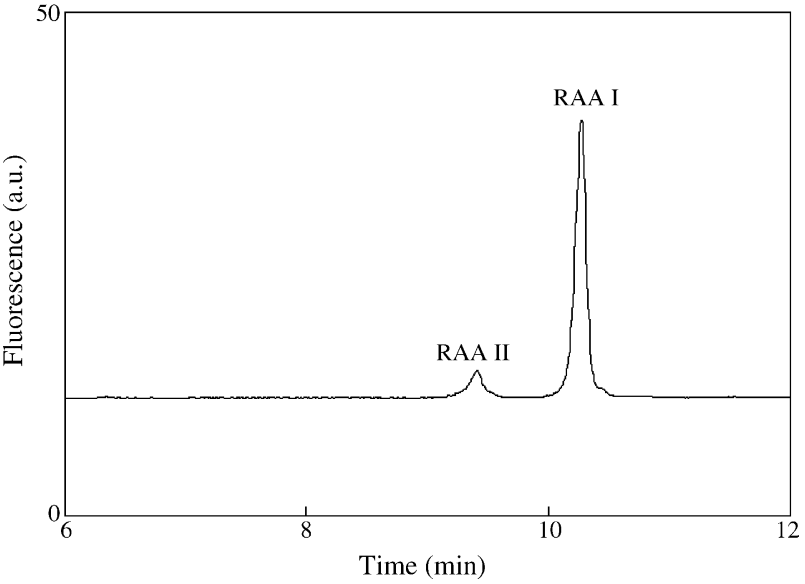

Fig. 3. Electropherogram of the separation of RAA-I and RAA-II by CE-LIF at $10 \mathrm{kV}$. Capillary: $40 \mathrm{~cm}$ in total length, and $30 \mathrm{~cm}$ in effective length; filled with $50.0 \mathrm{mM}$ sodium tetraborate $(\mathrm{pH} 9.0)$ containing $10.0 \mathrm{mM}$ SDS. The hydrodynamic injection was conducted at $20-\mathrm{cm}$ height for $10 \mathrm{~s}$. The RAA-I and RAA-II were reduced from OAA-I and OAA-II at the concentrations of $9.0 \times 10^{-7} \mathrm{M}$ and $10^{-7} \mathrm{M}$, respectively.

due to increases in the ionic strength. The peak widths for RAA-I and RAA-II were 0.32 and 0.24 min, respectively. As a result, a greater resolving power of 3.1 was obtained. The RSD values for the migration times of RAA-I and RAA-II were $0.5-0.7 \%$, respectively, while the RSD values of their corresponding peak heights were $5.3 \%$ and $4.5 \%$, respectively. The LODs at a S/N $=3$ for AA-I and AA-II were found to be 8.2 and $5.4 \mathrm{nM}$, respectively, when injected at $20-\mathrm{cm}$ height for $10 \mathrm{~s}$ (the electropherogram as shown in Fig. 3). The sensitivity is about two orders of magnitude higher than that obtained by CE with UV-vis absorption detection [27]. The result suggests that the present method is suitable for the analysis of AAs in medicinal plants and herbs.

\subsection{Analysis of medicinal samples and dietary supplements}

With a good resolving power and high sensitivity, the present CE-LIF approach was applied to the determination of AAs prepared from small amounts of samples. The AAs were prepared from $0.2 \mathrm{~g}$ powder samples, which are less than those $(1.0-5.0 \mathrm{~g})$ used in other methods $[22,25,27]$. We analyzed 61 medicinal samples and dietary supplements, in which 28 samples were sold from drugstores and 33 samples were from patients. Fig. 4 shows two representative electropherograms for the samples numbered 7 and 16 that are listed in Table 3. Because a UV-laser was employed in the CE-LIF system, only solutes with intrinsic fluorescence characteristics can be detected. As a result, there are only few peaks in the two electropherograms; minimizing interferences. The RSD values $(n=3)$ of the migration time for RAA-I and RAAII were less than $1.2 \%$ and $1.0 \%$ for the two samples. By applying a standard addition method, the concentrations of OAAs in the samples were determined and the results were

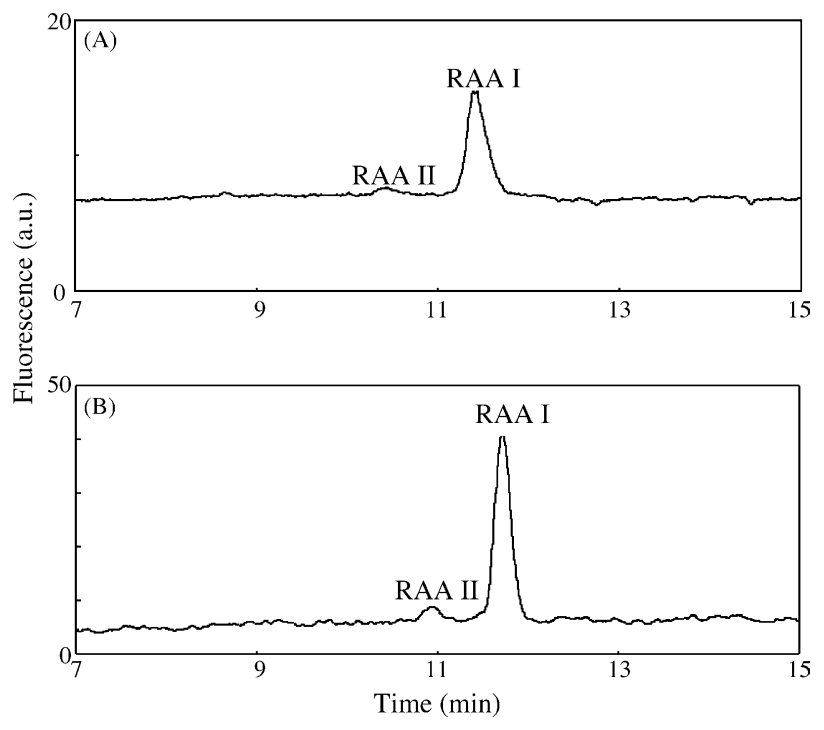

Fig. 4. Electropherograms for the separations of real samples: (A) and (B) samples are numbered 7 and 16 as listed in Table 3. Other conditions are the same as in Fig. 3.

Table 3

Determinations of AA-I and AA-II in medicinal samples and dietary supplements

\begin{tabular}{clrc}
\hline Samples & Product presentation & AA-I $(\mathrm{ppm})^{\mathrm{a}}$ & AA-II $(\mathrm{ppm})^{\mathrm{a}}$ \\
\hline From drugstores & & \\
1 & Powder & $5.0 \pm 1.0$ & $16.0 \pm 2.0$ \\
2 & Powder & $8.0 \pm 1.0$ & \multicolumn{1}{c}{${ }^{\mathrm{b}}$} \\
3 & Powder & $40.0 \pm 3.0$ & $2.0 \pm 0.1$ \\
4 & Tea bags & - & $3.0 \pm 0.2$ \\
5 & Powder & $120.0 \pm 8.0$ & $10.0 \pm 1.0$ \\
6 & Pills & $10.0 \pm 1.0$ & $1.0 \pm 0.1$ \\
7 & Powder & $40.0 \pm 3.0$ & $3.0 \pm 0.4$ \\
8 & Powder & $15.0 \pm 3.0$ & $2.0 \pm 0.1$ \\
From patients & & \\
9 & Powder & $20.0 \pm 2.0$ & - \\
10 & Powder & $8.0 \pm 1.0$ & - \\
11 & Powder & $20.0 \pm 2.0$ & - \\
12 & Powder & $50.0 \pm 4.0$ & - \\
13 & Powder & $65.0 \pm 5.0$ & $8.0 \pm 1.0$ \\
14 & Pills & $85.0 \pm 6.0$ & $10.0 \pm 1.0$ \\
15 & Powder & $5.0 \pm 1.0$ & $15.0 \pm 2.0$ \\
16 & Pills & $150.0 \pm 10.0$ & $12.0 \pm 1.0$ \\
17 & Pills & $45.0 \pm 4.0$ & $5.0 \pm 1.0$ \\
18 & Pills & $5.0 \pm 1.0$ & - \\
19 & Powder & $5.0 \pm 1.0$ & $3.0 \pm 0.3$ \\
20 & Powder & $32.0 \pm 3.0$ & $4.0 \pm 0.3$ \\
21 & Powder & $10.0 \pm 2.0$ & - \\
22 & Powder & - & $8.0 \pm 1.0$ \\
23 & Pills & $40.0 \pm 3.0$ & - \\
24 & Pills & $100.0 \pm 8.0$ & $10.0 \pm 1.0$ \\
\hline
\end{tabular}

${ }^{\mathrm{a}} n=3$.

b Were not detected.

c The medicine were obtained from patients who have taken the medicines for some time and have been diagnosed to have renal failure in the Shin Kong Wu Ho-Su Memorial Hospital. Samples 1-2 were from the same pharmaceutical factory. A series of samples from 9 to 12,13 to 15,16 to 18 were colleted from different patients, respectively. 
listed in Table 3. Of the 61 samples, 14 samples contained AA-I and AA-II, as well as 10 samples contained either AAI or AA-II. The results of the sample containing AAs are listed in Table 3, with the concentrations ranging from 1.0 to $150.0 \mathrm{ppm}$. The RSD values of the migration times for RAAI and RAA-II in different samples ranged from $1.0 \%$ to $2.5 \%$ and from $0.8 \%$ to $2.1 \%$, respectively. The RSD values for the peak heights corresponding to RAA-I and RAA-II were about $8.0 \%$ and $10.0 \%$, but some of them were greater than $10.0 \%$, mainly due to matrix effects and extremely low amounts of the AAs. We note that the molar concentrations of $1.0 \mathrm{ppm}$ AA-I and AA-II are $1.2 \times 10^{-8} \mathrm{M}$ and $1.3 \times 10^{-8} \mathrm{M}$, respectively. Although the present CE-LIF approach is sensitive and efficient, we could not rule out possible positive errors due to co-migration of other RAAs; there are more than 13 AA-related compounds found in real medicinal plants [22]. However, we could not test the possibility because they are unavailable in this lab.

Based on the data listed in Table 3, we conclude: (1) the contents of AA-I in various samples are much higher than those of AA-II in most cases; (2) the species of medicinal plants has an important impact on the distribution of the contents of AAs; (3) the samples from patients generally contain higher concentrations of AAs; (4) the data may support the connection of AAs to end-stage renal failure. We also conclude that the present CE-LIF approach is sensitive, simple, efficient, and accurate for the determination of RAAs in real samples.

\section{Conclusions}

The RAAs reduced from OAAs in $10.0 \mathrm{mM} \mathrm{HCl}$ containing iron powder exhibit fluorescence at $477 \mathrm{~nm}$ when excited at $390 \mathrm{~nm}$. By applying CE-LIF, the analysis of AA-I and AA-II was completed within $12 \mathrm{~min}$, with the LODs at 8.2 and $5.4 \mathrm{nM}$, respectively. Having the advantage of high sensitivity and resolving power, the present CE-LIF allows detection of trace AAs in a number of medicinal samples and dietary supplements. The successful analysis of 61 medicinal samples and dietary supplements shows that the present CELIF is practical for the determination of AA-I and AA-II in real samples, with the advantages of simplicity, rapidity, and reproducibility. However, more cases study may be needed in order to gain more insights into the fetal effects of AAs. In order to further improve the quantity for the analysis of AAs in trace levels, stacking techniques such as sweeping and using polymer solution should be worthy trying [36,37]. It is also interested in developing new techniques that allow analysis of DNA-AA adducts and provide greater resolving power for the analysis of various AAs.

\section{Acknowledgements}

This work was supported by Shin Kong Wu Ho-Su Memorial Hospital (SKH-8302-93-0305) and the National Science
Council of the Republic of China (NSC 93-2113-M-002015).

\section{References}

[1] J.L. Nortier, M.C. Munz Martinez, H.H. Schmeiser, V.M. Arlt, C.A. Bieler, M. Petein, M.F. Depierreux, L. De Pauw, D. Abramowitz, P. Vereerstraeten, J.L. Vanherweghem, N. Engl. J. Med. 342 (2000) 1686.

[2] M. Zhu, J.D. Philipson, Int. J. Pharm. 34 (1996) 283.

[3] C.S. Yang, C.-H. Lin, S.-H. Chang, H.-C. Hsu, Am. J. Kidney Dis. 35 (2000) 313.

[4] V.M. Arlt, M. Stiborova, H.H. Schmeiser, Mutagenesis 17 (2002) 265.

[5] J.L. Vanherweghem, M. Depirreux, C. Tielemans, D. Abramowitz, M. Dratwa, M. Jadoul, C. Richard, D. Vandervelde, D. Verbeelen, R. Vanhaelen-Fraste, Lancet 341 (1993) 387.

[6] J.L. Vanherweghem, J. Altern. Complem. Med. 4 (1998) 9.

[7] J.P. Cosyns, Drug Saf. 26 (2003) 33.

[8] T.-Y. Lee, M.-L. Wu, J.-F. Deng, D.-F. Hwang, J. Chromatogr. B 766 (2001) 169.

[9] Food and Drug Administration, Dietary supplements: aristolochic acid, accessed 25 September 2003, at http://www.cfsan.fda. gov/zdms/ds-bot.html.

[10] L.S. Gold, T.H. Slone, N. Engl. J. Med. 349 (2003) 1576.

[11] J.M. Pena, M. Borras, J. Ramos, J. Montoliu, Nephrol. Dial Transplant. 11 (1996) 1359.

[12] M. Stiborova, E. Freib, A. Breuer, M. Wiessler, H.H. Schmeiser, Mutat. Res. 493 (2001) 149.

[13] J.R. Ioset, G.E. Raoelison, K. Hostettmann, Planta Med. 68 (2002) 856.

[14] T. Seto, T. Hamano, H. Shioda, H. Kamimura, J. Health Sci. 48 (2002) 412.

[15] K.V. Rao, Y. Tanrikut, K. Killion, J. Pharm. Sci. 64 (1975) 345.

[16] R. Nishida, H. Fukami, J. Chem. Ecol. 15 (1989) 2549.

[17] T.-H. Tsai, C.-J. Chou, L.-C. Lin, W.-J. Tsai, C.-F. Chen, J. Liq. Chromatogr. 16 (1993) 1173.

[18] K. Hashimoto, M. Higuchi, B. Makino, I. Sakakibara, M. Kubo, Y. Komatsu, M. Okada, J. Ethnopharmacol. 64 (1999) 185.

[19] G.C. Kite, M.A. Yule, C. Leon, M.S.J. Simmonds, Rapid Commun. Mass Spectrom. 16 (2002) 585.

[20] T.-T. Jong, M.-R. Lee, S.-S. Hsiao, J.-L. Hsai, T.-S. Wu, S.-T. Chiang, S.-Q. Cai, J. Pharm. Biomed. Anal. 33 (2003) 831.

[21] S.-A. Chan, M.-J. Chen, T.-Y. Liu, M.-R. Fun, J.-E. Deng, M.-L. Wu, S.-J. Hsieh, Talanta 60 (2003) 679.

[22] J.R. Ioset, G.E. Raoelison, K. Hostettmann, Food Chem. Toxicol. 41 (2003) 29.

[23] Y.Z. Deng, N.W. Zhang, J. Henion, Anal. Chem. 73 (2001) 1432.

[24] X.Q. Ma, Q. Shi, J.A. Duan, T.T.X. Dong, K.W.K. Tsim, J. Agric. Food Chem. 50 (2002) 4861.

[25] Y.-R. Ku, Y.-S. Chang, K.-C. Wen, L.-K. Ho, J. Chromatogr. A 848 (1993) 537.

[26] H.-Y. Feng, L.-L. Yuan, S.F.Y. Li, J. Chromatogr. A 1014 (2003) 83.

[27] E.S. Ong, E.S.O. Woo, Electrophoresis 22 (2001) 2236.

[28] W. Li, S. Gong, D. Wen, B. Che, Y. Liao, H. Liu, X. Feng, S. Hu, J. Chromatogr. A 1049 (2004) 211.

[29] J.J. Parlow, A.M. Stevens, R.A. Stegeman, W.C. Stallings, R.G. Kurumbail, M.S. South, J. Med. Chem. 46 (2003) 4297.

[30] A.L. Gill, M. Frederickson, A. Cleasby, S.J. Woodhead, G. Maria, M.G. Carr, A.J. Woodhead, M.T. Walker, M.S. Congreve, L.A. Devine, D. Tisi, M. O'Reilly, L.C.A. Seavers, D.J. Davis, J. Curry, R. Anthony, A. Padova, C.W. Murray, R.A.E. Carr, H. Jhoti, J. Med. Chem. 48 (2005) 414.

[31] H.-S. Chen, H.-T. Chang, Electrophoresis 19 (1998) 3149. 
[32] H.H. Schmeiser, E. Frei, M. Wiessler, M. Stiborova, Carcinogenesis 18 (1997) 1055.

[33] M. Stiborova, E. Frei, B. Sopko, M. Wiessler, H.H. Schmeiser, Carcinogenesis 23 (2002) 617.

[34] D.B. Mix, H. Guinaudeau, M. Shamma, J. Nat. Prod. 45 (1982) 657.
[35] M. Sreedhar, Y.-W. Lin, W.-L. Tseng, H.-T. Chang, Electrophoresis 26 (2005), in press.

[36] J.P. Quirino, S. Terabe, Anal. Chem. 71 (1999) 1638.

[37] W.-L. Tseng, H.-T. Chang, Anal. Chem. 72 (2000) 4805. 